\title{
Large wood transport as significant influence on flood risk in a mountain village
}

\author{
V. Ruiz-Villanueva $\cdot$ J. M. Bodoque $\cdot$ A. Díez-Herrero $•$ \\ E. Bladé
}

Received: 7 December 2012/ Accepted: 6 May 2014/Published online: 14 May 2014

(C) Springer Science+Business Media Dordrecht 2014

\begin{abstract}
An important issue that is not considered in most flood risk assessments in mountain villages in Spain is the transport of solids associated with the flood flow, in this case, large wood transport. The transport and deposition of this wood in urban areas may be a potentially worse hazard than the flood flow itself. Despite its importance, large wood is a key ecological element in rivers, so removing it could be an unsuccessful approach. Therefore, efforts are needed in the better understanding of wood transport and deposition in streams. To analyse this process, scenario-based 2D hydrodynamic flood modelling was carried out. Since flood risk assessment has considerable intrinsic uncertainty, probabilistic thinking was complemented by possibilistic thinking, considering worst-case scenarios. This procedure obtained a probabilistic flood map for a 500-year return period. Then, a series of scenarios was built based on wood budget to simulate wood transport and deposition. Results allowed us to identify the main infrastructures sensitive to the passing of large wood and simulate the consequences of their blockage due to wood. The potential damage was estimated as well as the preliminary social vulnerability for all scenarios (with and without wood transport). This work shows that wood transport and deposition during flooding may increase potential damage at critical stream configurations (bridges) by up to $50 \%$ and the number of potentially exposed people nearby these areas by up to $35 \%$.
\end{abstract}

Keywords Flood risk · Large wood transport - Drift wood · Woody debris

\footnotetext{
V. Ruiz-Villanueva $(\bowtie) \cdot J$. M. Bodoque · A. Díez-Herrero · E. Bladé Geological Survey of Spain (IGME), Rios Rosas 23, 28003 Madrid, Spain e-mail: virginia.ruiz@dendrolab.ch

Present Address:

V. Ruiz-Villanueva

Dendrolab.ch, Institute of Geological Sciences, University of Bern, Bern, Switzerland
} 


\section{Introduction}

The transport and deposit of wood at critical stream configurations (i.e. bridges) can cause a quick succession of backwater effects due to the reduction of cross-sectional area, accompanied by bed aggradation, channel avulsion and local scouring processes, which can ultimately lead to embankment/bridge collapse and floodplain inundation (Diehl 1997; Comiti et al. 2007; Lyn et al. 2007; Mao and Comiti 2010; Comiti et al. 2012). As a result, flooded areas are likely to be different from those predicted from models where the presence of wood is not considered (see an example in Ruiz-Villanueva et al. 2012), and therefore, this may result in the incorrect/uncertain estimation of flood risk. This potential conflict between large wood and infrastructures may be particular important in urban areas, where the problem has to be redefined as the inability of infrastructures to pass large wood (Lassettre and Kondolf 2012; Schmocker and Hager 2011).

A common management response is to remove living vegetation and dead wood from the channels (Bradley et al. 2005). In natural conditions, floods are the mechanisms regulating the river environment, and extensive literature now exists describing the positive influence of wood on stream ecology (Martin and Benda 2001). In addition, it has been demonstrated that large wood removal could fail, in part because of new inputs of wood during floods (Young 1991; Gippel 1995; Dudley et al. 1998). However, the presence of infrastructure on the channels, and the progressive alteration of the hydrogeomorphology and land use of banks and floodplains have led to an exponential increase in channel cleaning, which is now the subject of ongoing debate in some countries (Ollero 2013). The challenge nowadays is thus to maintain the equilibrium of the good ecological and hydromorphological condition of rivers and at the same time analyse and manage the potential risks.

A wide range of factors can lead to uncertainty in flood risk estimation, but all of them can be divided into two main types (Tung and Yen 1993; Paté-Cornell 1996): (A) Natural variability (random uncertainty): refers to uncertainties associated with the inherent randomness of natural processes; (B) Knowledge uncertainty (epistemic uncertainty): results from incomplete knowledge of the system under consideration and is related to the ability to understand, measure and describe the system (model, parameter and data uncertainties). Knowledge or epistemic uncertainty can be reduced by acquiring more knowledge, while natural variability is inherent in the system and cannot be reduced by more detailed information. However, it is possible to include it in flood risk analysis (Apel et al. 2004). According to the literature, flood maps can be produced using either deterministic or probabilistic approaches (Bates et al. 2004; Merz et al. 2007; Di Baldassarre et al. 2010). Deterministic approaches do not normally take the uncertainties into account (Bates et al. 2004). In addition, hydrological and other data are often far from complete, their reliability is usually not perfect, and they can be analysed in different ways, resulting in slightly or very different outcomes (Faulkner et al. 2007). This may therefore lead to incorrect hazard assessment. The analysis of different scenarios (Mazzorana et al. 2011) and the what if method (Yeo 1998) may also be used to estimate the variables, factors and parameters considering the most likely values.

The aim of this article, therefore, was to analyse how the transport and deposition of wood influence flood risk estimation in a mountain village using the worst-case scenario approach. The studied river basin was identified as prone to wood delivery in a previous stage (Ruiz-Villanueva et al. 2014b). In addition, we tried to take the uncertainties mentioned above and to obtain the optimal (most likely) flood risk estimate for the cases where no wood was present and for different large wood transport scenarios. 


\section{Study area}

The study area is located in the eastern massif of the Sierra de Gredos (in the south of Avila province), the highest section (Almanzor Peak 2,592 m a.s.1.) of the Spanish Central System, which crosses the Iberian Peninsula SW-NE (Fig. 1). These mountains are the natural division between the river basins of the Tajo (Tagus) to the S. and Duero to the N. The sector of Sierra de Gredos studied here is on the southern slopes, in the basin of the Tiétar, a tributary of the Tajo. We studied a reach of the Arenal, a tributary of the Tiétar.

The Arenal flows through the town of Arenas de San Pedro ( 6,900 inhabitants). The drainage area at Arenas de San Pedro is $67 \mathrm{~km}^{2}$, and the total length is $12.5 \mathrm{~km}$. The study reach is $1.2 \mathrm{~km}$ long (see Table 1), and the river flows in nearly natural conditions (since there are no dams upstream), although part of the reach is channelled.

The geology of this region is mainly composed of granites (Upper Palaeozoic granitoids) covered by a sandy weathering mantle; the Arenal river bed consists mainly of gravel, with some bedrock outcrops.

There is abundant forested mass in the area (Fig. 2), and different species are found depending on altitude. At higher altitudes, where the extreme climatic characteristics impede the development of tree or shrub species, grassland cover is found (mainly Festuca sp., Carex sp.). At lower levels, there is a characteristic presence of shrubs (Cytisus sp.) and stretches of high mountain conifers such as Pinus sylvestris. This species is replaced at lower altitudes by Pinus pinaster which usually appears with Genista florida, Ilex aquolifolium, Erica arborea and Sorbus aucuparia. Further down, the forest is composed
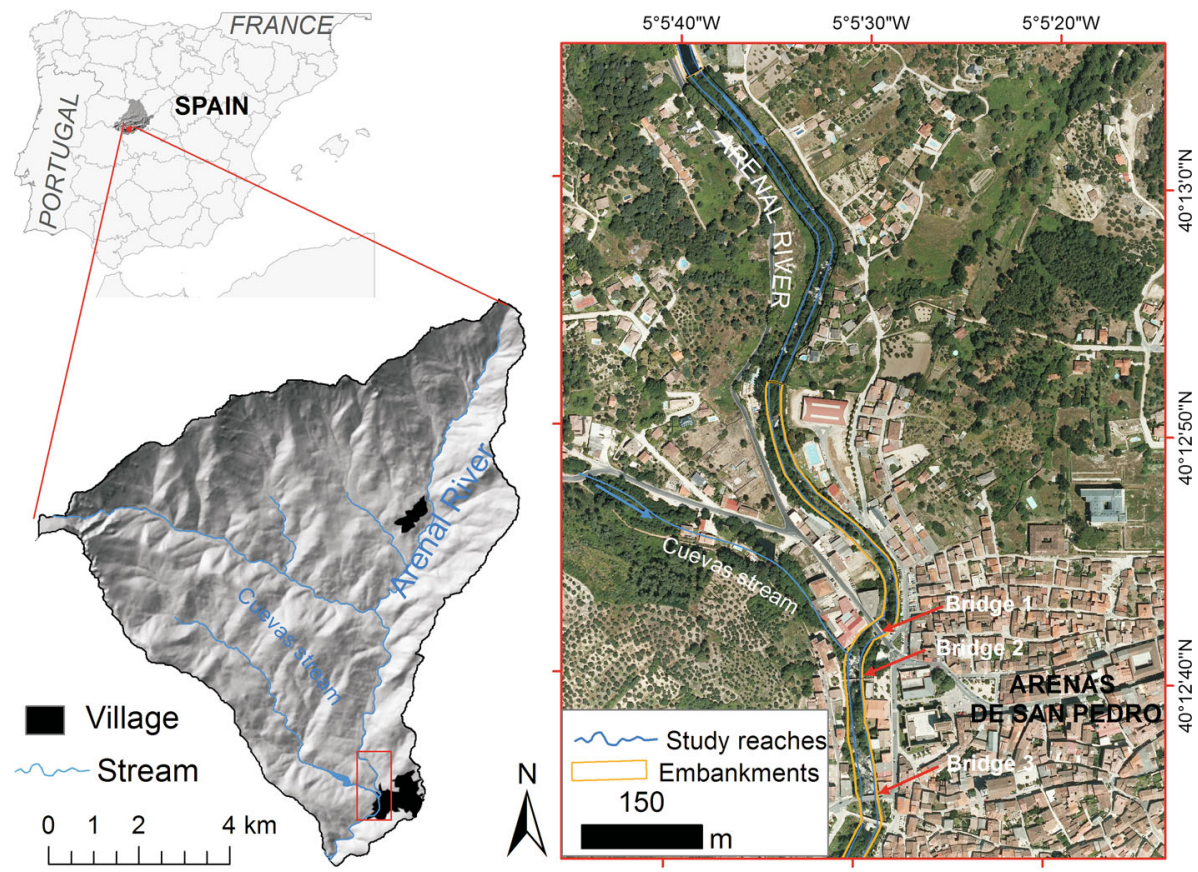

.NE

Fig. 1 Location of the study site. There are three bridges along the studied reach, and the Cuevas tributary stream joins the Arenal in mid-reach 
Table 1 Main morphometric characteristics of the Arenal river basin and the studied reach

\begin{tabular}{ll} 
Arenal river at Arenas de San Pedro & \\
\hline Drainage area $\left(\mathrm{km}^{2}\right)$ & 67 \\
River length $(\mathrm{km})$ & 12.5 \\
Maximum basin altitude (m a.s.1.) & 2,200 \\
Minimum basin altitude (m a.s.l.) & 400 \\
Average stream slope & 0.14 \\
Time concentration (h) & 2.95 \\
Studied reach length (km) & 1.2 \\
Studied reach maximum altitude (m a.s.l.) & 545 \\
Studied reach minimum altitude (m a.s.l.) & 489 \\
Studied reach average stream slope (mm & -1 )
\end{tabular}

mainly of deciduous trees such as Quercus pyrenaica and Quercus ilex. The riparian vegetation is predominantly Alnus glutinosa and Fraxinus angustifolia. Tree clearance has been carried out in the past in the study area and is still on going.

The climate of the study area is determined by the frequent arrival of Atlantic depressions from the SW during autumn, winter and spring and by the predominant Azores anticyclone causing very dry summers (only $10 \%$ of annual precipitation). The yearly precipitation recorded in the area is around 2,000 $\mathrm{mm}(1,913 \mathrm{~mm}$ at $800 \mathrm{~m}$ a.s.l.).

Flash floods are common in the Arenal catchment area boosted by heavy rains and the high stream gradient $\left(>0.02 \mathrm{~mm}^{-1}\right)$, which lead to extremely high discharge and potentially wood transport rates.

\section{Methodology}

The general methodological approach was designed to analyse flood risk in a mountain village incorporating wood transport into the analysis. As mentioned in the introduction, the risk analysis itself is accompanied by several sources of uncertainty. To consider these uncertainties in the analysis, the methodology was divided into four steps (Fig. 3):

1. Step 1: For the flood frequency analysis (FFA), a Bayesian Markov Chain Monte Carlo (MCMC) procedure (Reis and Stedinger 2005) was used. This approach can account for uncertainties in hydrological extremes as it provides estimates of confidence bounds for the estimated quantiles (Gaál et al. 2010).

2. Step 2: Model performance and water depth reconstruction were analysed under uncertainty of the input Manning roughness coefficient values and the accuracy of the digital elevation model used for 2D hydrodynamic simulation.

3. Step 3: The role of large wood transport during floods was included in the analysis by modelling different scenarios.

4. Step 4: Damage functions with predictive bounds and flood hazard thresholds were used to estimate the 500-year flood risk in terms of expected or potential direct damage (Messner and Meyer 2005) and in terms of danger or hazards for people (HR Wallingford 2005). 


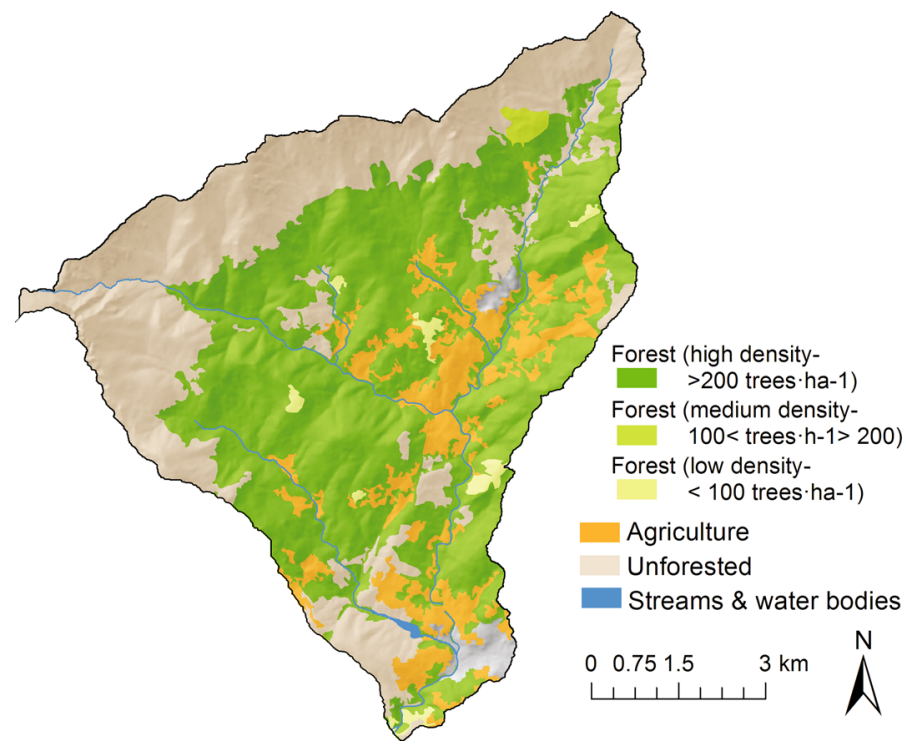

Fig. 2 Vegetation distribution in the Arenal River Basin
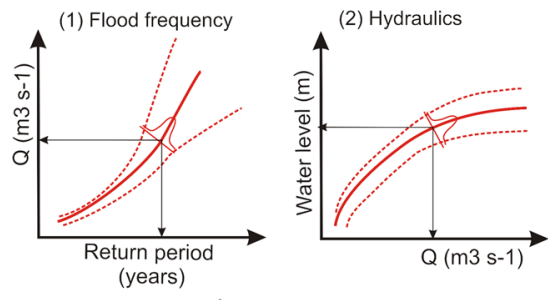

\section{FLOOD RISK ESTIMATION}

(3) Flood modelling
LWD scenarios

Scenario 1: Qt

Scenario 2: Qt+LWD

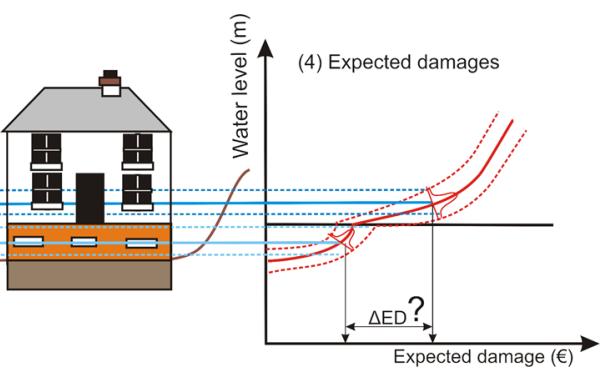

Fig. 3 Scheme of methodological approach for flood risk estimation. Qt is a given return period discharge; $L W$ large wood transport

Therefore, the flood risk is estimated as:

$$
R=P\left(\frac{Q^{\prime}}{P^{\prime}}\right) \cdot P\left(\frac{Z^{\prime}}{Q^{\prime}}\right) \cdot P\left[\frac{S^{\prime}}{Z_{0}-Z^{\prime} \leq 0}\right] \cdot S^{\prime}
$$

The probabilities describe the following uncertainties: $P\left(Q^{\prime} / P^{\prime}\right)$, uncertainty in the discharge-probability relationship; $P\left(Z^{\prime} / Q^{\prime}\right)$, uncertainty in the stage-discharge relationship (model performance); $P\left[S^{\prime} /\left(Z_{0}-Z^{\prime} \leq 0\right)\right]$ : uncertainty in the stage-damage relationships.

If no uncertainties are taken into account, then risk is defined as:

$$
R=P S^{\prime}
$$

where $S^{\prime}$ is the consequences (damage potential); $P$ is the probability of hazard occurrence (probability of the flood event). 


\subsection{Extreme value statistics: flood frequency analysis}

As several studies have indicated, the major source of uncertainty in flood risk assessment has to be expected in extreme values statistics (Merz et al. 2002). The Arenal river basin at Arenas de San Pedro is ungauged, so no flow measurements were available. We used a compilation of historical discharges estimated using rainfall run-off methods and accounting for uncertainties related to antecedent conditions and land-use changes. These historical floods were reconstructed from documentary sources and tree-ring analysis (described in detail in Ruiz-Villanueva et al. 2013). Then, the Bayesian Markov Chain Monte Carlo (MCMC) procedure (Reis and Stedinger 2005) was applied accounting for uncertainties in discharge estimates and providing confidence bounds for the obtained quantiles (Gaál et al. 2010; Gaume et al. 2010). Through the incorporation of several subsets of data on historical floods with associated uncertainty, the influence of varying approaches on the estimation of quantiles in at-site analyses provided the related variability.

\subsection{D-hydrodynamic modelling}

The hydrodynamic simulation was carried out applying the IBER two-dimensional hydrodynamic software (Bladé et al. 2012; www.iberaula.es), developed by CIMNE, GEAMA group (UDC) and Flumen Research Institute (UPC). IBER is a numerical tool for 2D simulation of turbulent free surface unsteady flow and sediment transport in watercourses. IBER uses the finite volume method, which is widely used in computational fluid dynamics (Leveque 2002; Versteeg and Malalasekera 2007). To solve the hydrodynamics, the finite volume method with a second order Roe Scheme (time explicit scheme) is used on non-structured meshes. This method is especially suitable for flows in mountain rivers, where shocks and discontinuities can occur giving very sharp hydrographs. The method is conservative even when wetting and drying processes take place.

The reach geometry was produced by topographical survey using a combination of differential GPS and total station to obtain a detailed digital elevation model (DEM) with a pixel size equal to $1 \mathrm{~m}$ and vertical accuracy equal to $10 \mathrm{~cm}$.

Since there was a lack of data for model calibration, the water depth in the studied reach was analysed under uncertainty of the topographical accuracy and input Manning roughness coefficient values. The range of possible roughness unit values was defined following the criteria established by Chow (1959) and adapted for mountain streams by Jarret (1990). Assuming that there is a statistical distribution of possible values of the Manning coefficient defined by a normal distribution, the distribution parameters are $N\left(\mu, \sigma^{2}\right)$. In the fuzzy set, universe $\pm 2 \sigma^{2}$ was selected to achieve a confidence interval of $95 \%$.

\subsection{Wood transport recruitment and 2D hydrodynamic wood transport simulation}

In forested mountain catchments, the supply of large wood (LW) may be caused by a variety of mechanisms including landslides, floods and bank erosion (May and Gresswell 2003; Swanson 2003). Potentially recruited wood volumes (in terms of number of trees; $\mathrm{Vw}$ ) were estimated depending on the recruitment process severity, but focused on fluvial transport during floods as the main recruitment process. The estimation was carried out following the methodology proposed by Ruiz-Villanueva et al. (2014a). A GIS was used to obtain a spatially distributed analysis of potential LW source areas and to estimate potential wood volumes (such as the number of trees that may contribute wood to the 
channel throughout the basin). Multi-criteria together with fuzzy logic principles were used to define reliable scenarios, classifying areas by the likelihood of wood material recruitment based on potential recruitment processes, vegetation resistance and abundance. For the three main species in any given area, the total canopy cover $\left(\mathrm{Cc}_{i}\right)$ was extracted from the Forest Map of Spain and National Forest Inventory produced by the Ministry of the Environment (MFE 2011). The tree density (expressed as number of trees per area) is called relative density $\left(D_{i}\right)$ and is used together with species occupation and canopy cover to estimate the final number of trees in a given area. $\mathrm{Ca}_{i}$ is the contributing area defined for a specific recruitment process: $\mathrm{Vw}_{i}=\mathrm{Ca}_{i} \cdot \mathrm{Cc}_{i} \cdot D_{i} \cdot F_{\mathrm{c}}$.

In the delineated source area, the probability of a tree entering the stream may vary (Robison and Beschta 1990). This variability was incorporated into the method using a volume correction factor $\left(F_{\mathrm{c}}\right)$, which takes into account vegetation resistance to being recruited (based on species and stay) and the severity of the recruitment mechanism. This is equivalent to a recruitment probability and can be $1,0.5$ or 0.1 ; here it was computed by means of fuzzy logic matrices. This factor therefore reduces the total number of trees of recruitable wood in those areas where the severity of the process is lowest and/or vegetation resistance highest. Once the number of recruited trees is assessed, the number of logs can be estimated taking into consideration the occurrence of breakage using a coefficient $k$ : $\log s=k \cdot \mathrm{Vw}_{t}$. We estimated the number of trees and $\operatorname{logs}$ using $k=1$. However, uncertainty exists regarding this assumption.

Based on knowledge of the riparian vegetation, ranges were established for wood diameters, wood density and lengths of pieces.

A numerical model was developed and integrated in the 2D IBER model to simulate the hydrodynamics and wood transport (a detailed description can be found in Ruiz-Villanueva et al. (2014a); only a brief description is provided here). The model calculates the position and velocity of different size logs (assuming that they are cylinders) based on the balance of forces involved in wood motion: (1) the gravitational force acting on the log, equal to the effective weight of the $\log$ in a downstream direction; (2) the friction force in the opposite direction of the flow, which is equal to the normal force acting on the $\log$ multiplied by the coefficient of friction between the wood and the bed; (3) and the drag force, also acting in the direction of the flow, which is the downstream drag exerted on the $\log$ by the water in motion. The combination of these three forces yields the force balance at incipient motion for a circular cylinder lying on the river bed: $F_{\mathrm{f}}=F_{\mathrm{g}}+F_{\mathrm{d}}$; which is equal to:

$$
\begin{aligned}
& \left(g \cdot \rho_{\mathrm{w}} \cdot L_{\mathrm{w}} \cdot A_{\mathrm{w}}-g \cdot \rho \cdot L_{\mathrm{w}} \cdot A_{\text {sub }}\right) \cdot\left(\mu_{\text {bed }} \cdot \cos \alpha-\sin \alpha\right) \\
& =U_{\text {flow }}^{2} / 2 \cdot \rho \cdot C_{\mathrm{d}} \cdot\left(L_{\mathrm{w}} \cdot h \cdot \sin \theta+A_{\text {sub }} \cdot \cos \theta\right)
\end{aligned}
$$

where $L_{\mathrm{w}}$ is the piece length, $\rho_{\mathrm{w}}$ and $\rho$ are the wood and water densities, respectively, $\alpha$ is the angle of the channel bed in the direction of the flow, $g$ is gravity, $A_{\mathrm{w}}$ is the area of the $\log$ perpendicular to the piece length, $h$ is the water depth, and $C_{\mathrm{d}}$ is the drag coefficient of the wood in water.

The movement of logs includes two possible transport regimes (i.e. floating or sliding and rolling) based on wood density; and when floating, both translation and rotation, due to the fact that one end of the piece of wood is moving faster than the other end (based on flow velocity field), causing the piece to rotate towards a more flow-parallel orientation.

Interactions between logs and the channel configuration and among logs themselves are also taken into account in the model. Therefore, log velocity and trajectory may change due to contact with the banks or with other logs. If one moving piece of wood meets 
another piece (floating or resting), the two may collide and continue moving at a different velocity. Moreover, when a piece of wood reaches the bank, it can be entrapped, the driving forces decrease due to the reduction of the submerged area, but the resisting forces are still active around the log, and therefore, the initial motion condition is re-calculated.

The wood jam formation is a $3 \mathrm{D}$ process; however, this $2 \mathrm{D}$ model attempts to reproduce a quasi-3D process. If a log is lying (resting) on the river bed or bank and another piece floats above it, these two may interact, depending on the water depth and log diameters, and the lying log may start to move or the floating log may stop according to the force balance.

The hydrodynamics and wood transport are computed in two related ways; thus, the hydrodynamics influence the wood transport, but the presence of wood also influences the hydrodynamics. A drag force is included in the flow model as an additional term in the Saint-Venant equations, similar to roughness. This force is included as an additional shear stress at every finite volume, resulting from the presence of logs: $\tau_{\text {wood }, i}=\frac{\sum_{\log s} F_{\mathrm{d}}}{A_{i}}$ where $\tau_{\text {wood }, i}$ is the shear stress at every finite volume, or mesh element, $I$; $F_{\mathrm{d}}$ the drag forces; and $A_{i}$ the volume of the 2D finite volume, or area of mesh element $i$, that is: $\tau_{\text {wood }, i}=\left[\sum_{\log s}\left(U-U_{\log }\right)^{2} / 2 \cdot \rho \cdot C_{\mathrm{d}} \cdot\left(L_{\mathrm{w}} \cdot y \cdot \sin \theta+A_{\text {sub }} \cdot \cos \theta\right)\right] / A_{i}$ where $U$ is the water velocity; $U_{\log }$ is the component of the log velocity in the direction of the flow. In this model, drag coefficient $C_{\mathrm{d}}$ is assumed to be constant (we assigned a value of 1.2 according to Manga and Kirchner 2000; Brooks et al. 2006; Bocchiola et al. 2006), but the method allows its value to be changed in each simulation.

A series of scenarios was then simulated assuming that peak wood transport occurred just before and during peak discharge and varying the distribution of the wood budget (according to the three transport regime definitions proposed by Braudrick et al. 1997):

- Scenario 1. Uncongested transport: low, steady wood load entering during peak discharge. Piece-to-piece contact between logs occurring rarely or not at all during movement. Logs typically occupy $<10 \%$ of the channel area.

- Scenario 2. Semi-congested transport: medium, steady wood load entering during peak discharge. Some logs moving individually and others moving in clumps. Logs normally occupy $10-33 \%$ of the channel area.

- Scenario 3. Congested transport: high wood load entering during peak discharge. Little spacing between logs. Logs normally move as almost a single mass occupying more than $33 \%$ of the channel area.

In possibilistic terms, Scenario 1 is more likely to occur than Scenario 3 which is unlikely and the worst-case scenario. Since there was no information on the initial wood conditions, no logs were placed in the reach at the initial time step.

\subsection{Potential flood damage and risk to population}

The concept of damage functions is central to flood damage estimation, relating damage to each element at risk to the flood characteristics (i.e. flood maps and land-use maps reflecting the type and the density of objects at risk). For physical assets such as buildings (contents and structure), the relative functions (Kreibich et al. 2010) provide susceptibility expressed as a percentage of the total asset value. In most flood damage models, the resulting damage is obtained from the type or use of the element at risk and the water depth 
(Wind et al. 1999; NRC 2000). Flood damage potential is used here as potential damage in a flood-prone area. Sometimes this term is used as synonymous with expected flood damage (flood damage figures estimated before a flood event) in the context of flood risk management (Messner et al. 2007). Therefore, we evaluated the impacts of the flooding related to structural damage to buildings and properties based on depth-damage functions. We revised available catalogues of residential depth-damage functions (USACE 1992; Patricova 2002; Ballesteros-Canovas et al. 2013), and to estimate the impacts, GIS tools based on statistical and spatial analysis were used following the guidelines proposed by Kang et al. (2005).

All data used for our analysis are publicly available and updated. Most of the data were obtained from municipal statistics (census and social data, Arenas de San Pedro). Seven single land-use types were used for elements at risk: residential buildings (single storey, multi-storey, with and without basement), industrial areas, agricultural areas (mainly fruit and olive trees), and sports or recreation areas. Since there is a large riverside parking area, potential damage to vehicles was also taken into account in terms of damages due to inundation. Damage caused by impacts of the transported woody pieces is out of the scope of this work, but it could increase the economic losses. To estimate the damage, we used the average market replacement price for Arenas de San Pedro for residential and industrial buildings, cars, and sport or recreation areas. For residential and industrial uses, the financial value of structural damage was taken as $15 \%$ of the average building price; the value of contents damage was assessed as $20 \%$.

Recent literature on natural hazards highlights the significance of the social dimension in hazard and related risk analysis (Haque and Etkin 2007). In these situations, human safety is at risk when people are exposed to flows which exceed their ability to remain upright or to cross a waterway. In recent years, several numerical and laboratory-based experimental studies have been undertaken to define the limits of human stability within differing flow regimes (Gómez et al. 2010; Russo et al. 2011). Human stability has been found to be influenced by numerous factors, but there is broad agreement that the flood hazard level (defined as flood conditions causing people to be swept away) is primarily related to velocity $(v)$ and depth $(y)$ and several authors have proposed different ratios between these two parameters to express hazard levels in floods (Abt et al. 1989; Reiter 2000; Kelman et al. 2002; Shand et al. 2010). This dimension was therefore introduced using depth-velocity functions (HR Wallingford 2005) to assess the human risk threshold. Although to date velocity has rarely been taken into account in damage evaluation, we attempted to include it in the analysis by means of hazardousness or dangerousness for people. Some additional observations regarding population statistics were also analysed.

\section{Results}

\subsection{Expected 500-year flood event and wood budget}

The compiled discharge data series used in previous work were used as explained for the frequency analysis. As a first stage, the data were processed as instrumental records in the MCMC frequency analysis, and then trials were run with some of the events as instrumental and others as historical, including the estimated uncertainty through an iterative process. Some results of this iterative process are summarized in Table 2.

According to the differences in quantile estimates, an average value of $769 \pm 252 \mathrm{~m}^{3} \mathrm{~s}^{-1}(32 \%)$ represents the variability in the estimated 500-year flood 
Table 2 Arenal river at Arenas de San Pedro village estimation of the discharge quantiles $Q(\mathrm{ML})$ corresponding to the return period $T=500$

\begin{tabular}{lcll}
\hline FFA settings & $Q(\mathrm{ML})$ & $\mathrm{CI}_{0.05}$ & $\mathrm{CI}_{0.95}$ \\
\hline FFA 1 & 476 & 406 & 1,020 \\
FFA 2 & 413 & 405 & 609 \\
FFA 3 & 424 & 368 & 943 \\
FFA 4 & 1,129 & 889 & 1,518 \\
Mean & 610 & 517 & 1,022 \\
Regional model & 641 & - & - \\
\hline
\end{tabular}

$\mathrm{CI}_{0.05}\left(\mathrm{CI}_{0.95}\right)$ is the $5 \%(95 \%)$ confidence limit of the estimates $Q(\mathrm{ML})$

discharge. The maximum likelihood estimated value was $610 \mathrm{~m}^{3} \mathrm{~s}^{-1}$, and values of 517 and $1,022 \mathrm{~m}^{3} \mathrm{~s}^{-1}$ as 5 and $95 \%$ confidence limits respectively.

For the Cuevas tributary stream, since there is a dam upstream of its confluence with the Arenal, we assumed the maximum discharge without overflooding to be $205 \mathrm{~m}^{3} \mathrm{~s}^{-1}$.

Manning coefficient values were assigned to each cell of the mesh, ranging from 0.011 to $0.019 \mathrm{~m}^{1 / 2} \mathrm{~s}^{-1}$ in the built-up area, from 0.066 to $0.189 \mathrm{~m}^{1 / 2} \mathrm{~s}^{-1}$ for forested areas, $0.06-0.14 \mathrm{~m}^{1 / 2} \mathrm{~s}^{-1}$ for vegetated banks, and $0.023-0.084 \mathrm{~m}^{1 / 2} \mathrm{~s}^{-1}$ in the main channel where large boulders were present.

The combination of the flood frequency results with the Manning values distribution allowed us to obtain a probabilistic map for the expected flood-prone area for the 500-year flood (Fig. 4).

Wood transport scenarios were built based on the parameters (discharge and Manning roughness values) used for the $90 \%$ probability inundation map.

The wood-contributing areas were identified, and the probability of vegetation being recruited from them was assigned. Together with vegetation density and canopy cover, estimations of potentially recruitable wood budget could be used as input for the model (Fig. 5).

According to this estimation, the maximum potentially recruitable wood is around 9,800 logs for the entire basin $\left(19,500 \mathrm{~m}^{3}\right.$ or $290 \mathrm{~m}^{3} \mathrm{~km}^{-2}$; assuming $0.65 \mathrm{~m}$ as average diameter and $6 \mathrm{~m}$ average length). For the defined transport scenarios, we reduced the computed wood budget to the drainage area upstream from the study site and to the El Arenal village located upstream from Arenas de San Pedro (see Fig. 1), where we assume that wood recruited upstream will be deposited. This reduces the maximum number of logs up to $3,100\left(6,100 \mathrm{~m}^{3}\right)$. This amount is distributed in time, as explained in the methodology.

When wood enters the simulation, the main effect is the backwater effect upstream of the bridges where the wood is entrapped and deposited, reducing the cross-sectional area, and as a result the water depth increases significantly nearby these areas. Figure 6 shows this backwater effect for the SC3.

In addition, we could observe the simulated wood deposits and identify the most sensitive cross-sections. According to results of the model, bridge 1, which is the bridge located farthest upstream, is the main critical section and where the largest amount of wood is trapped (Fig. 7). In this section, the water depth increases up to $3 \mathrm{~m}$, flooding the nearby areas; in the bridge 2 section the water also floods the channelization increasing the water depth due to wood deposits up to $1 \mathrm{~m}$. Finally, water depth in the bridge 3 section increases 


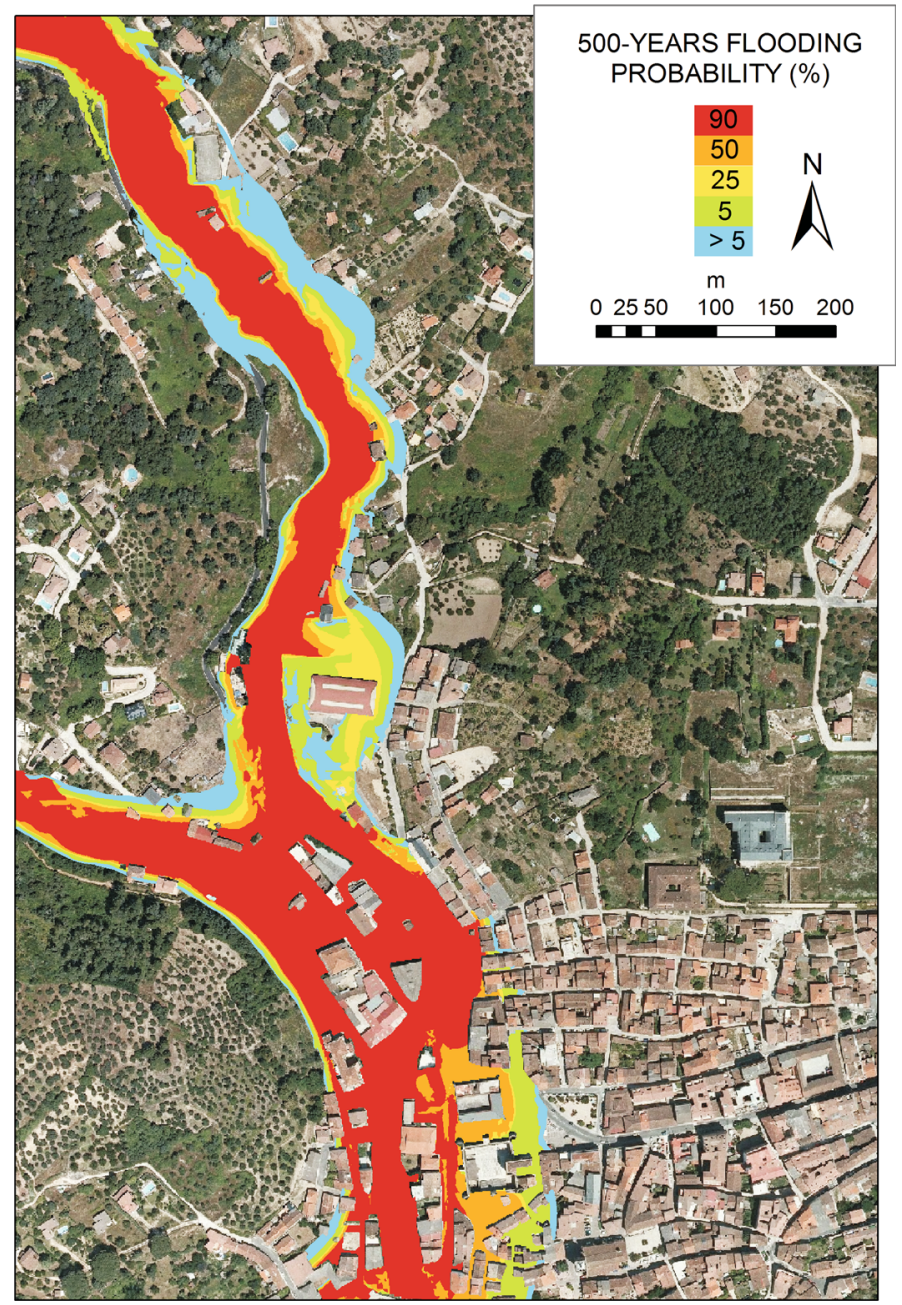

Fig. 4 Probabilistic inundation map (without wood transport) for 500-year flood

up to $4 \mathrm{~m}$ for the SC3. These increments may be equivalent to values obtained with discharges of clear water (without wood) corresponding to a higher return period event.

The design of bridge 1, together with the fact that is the first infrastructure of the studied reach, could be the reason that it is easily clogged. The geometry of the stone and concrete bridge with lateral abutments, closed spandrel deck arch and a small culvert represents a big obstacle to wood transport and causes wood to be easily deposited. In addition, the bridge crosses over a river bend and the small culvert (see detail in Fig. 7) is located at the inner part of the bend, which means wood is deposited mainly in the area upstream of the culvert. Note that basement windows are not very high up in the buildings located in this reach. Bridge number 3 (stone and concrete arch bridge, see Fig. 7) is also partially blocked, as can be seen in the figure, while bridge 2 (a small pedestrian pony truss bridge) 


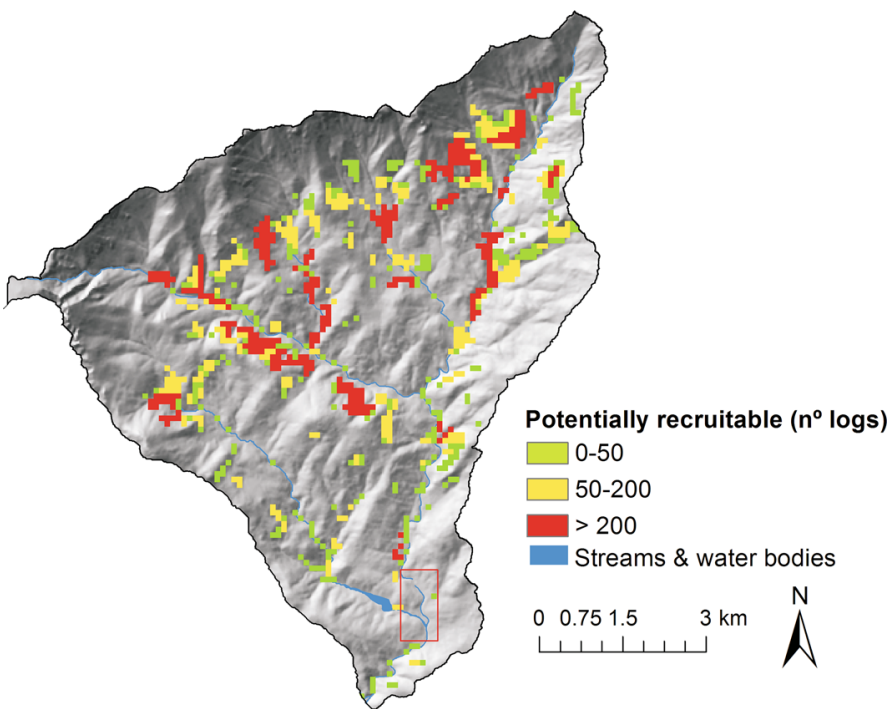

Fig. 5 Number of logs potentially recruitable as large wood to streams, based on landslides, floods and bank erosion processes, connectivity to streams and vegetation stand and density in the Arenal River basin

allows wood to pass. Table 3 summarizes all these geometrical characteristics and the water depth for all scenarios.

Therefore, this potential inability of infrastructures to pass large wood should be taken into account in river management.

\subsection{Potential damages with and without wood transport scenarios}

The financial replacement value for damage estimation was based on average market prices for this town: residential buildings $-1,200 € \mathrm{~m}^{-2}$; industrial buildings-1,400€ $\mathrm{m}^{-2}$; vehicles-12,000 $€$; sport and recreation areas $-60 € \mathrm{~m}^{-2}$. For residential and industrial uses, the financial value of structural damage was taken as $15 \%$ of the average building price and the value of contents damage as $20 \%$, based on insurance data and previous studies (PATRICOVA 2002; Ballesteros-Canovas et al. 2013; Fig. 8).

Seven land-use types were analysed, with most buildings in type 3: single storey without basement; type 4: multi-storey without basement; and type 9: industrial. These three types were therefore used for further analysis (Fig. 9).

The total estimated expected damage in Arenas de San Pedro for the 500-year flood (probability equal to 0.002 ) without wood transport is up to $14,000 € \mathrm{~m}^{-2}$ affected area (with $85 \%$ probability). When wood transport is simulated, these values change to up to $21,000 € \mathrm{~m}^{-2}$ (Fig. 10).

Arenas de San Pedro has a total area of approx. $195 \mathrm{~km}^{2}$ with 6,874 inhabitants, $49.25 \%$ male and $50.75 \%$ female (INE 2008 and municipal census data). A population analysis by age shows that $1,535(22.33 \%)$ are under $25 ; 2,581(37.54 \%)$ are $25-50$; $1,549(22.53 \%)$ are $50-70$; and 1,209 $(17.58 \%)$ are over 70 . A total of $29.15 \%$ of the population is considered as dependant (over 65 or under 18). There are at least 453 illiterate inhabitants $(6.6 \%)$; 961 (13.4\%) with no formal education; 1,613 (23.46\%) with basic qualifications; $187(2.7 \%)$ university graduates; approx. $605(8.8 \%)$ are 


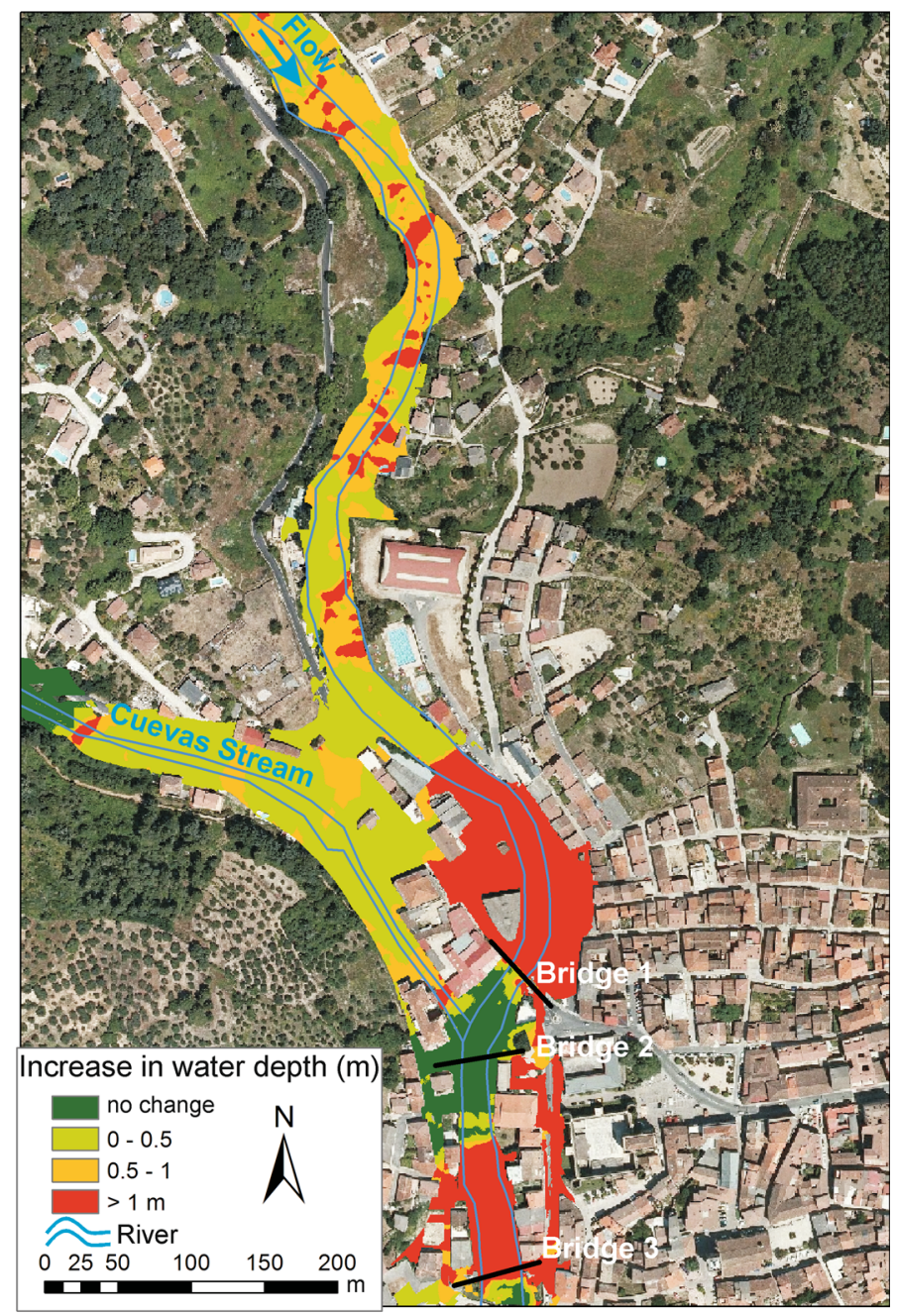

Fig. 6 Water depth (in metres) change between the $90 \%$ probabilistic flooding map without wood, and scenario 3 of wood transport and deposition. Black arrows show bridge locations

unemployed (2,008 census data). There are approx. 2,358 households (usual residence) with an average two occupants over 35 and one 16-34. The second most common type of household has 2 occupants with at least one over 65 .

These statistics suggest that approx. $30 \%$ of the population is highly vulnerable, and based on the flood simulations without wood transport, a minimum of 105 residential buildings would be affected, with $50 \%$ of these multi-storey; assuming that each storey is one household, with an average 3 residents per house, the minimum number of people potentially affected by flooding is 400 (with 120 of these highly vulnerable). If we take into account the worst-case wood transport scenario, these figures increase to 120 buildings with 540 (162 highly vulnerable) inhabitants. 


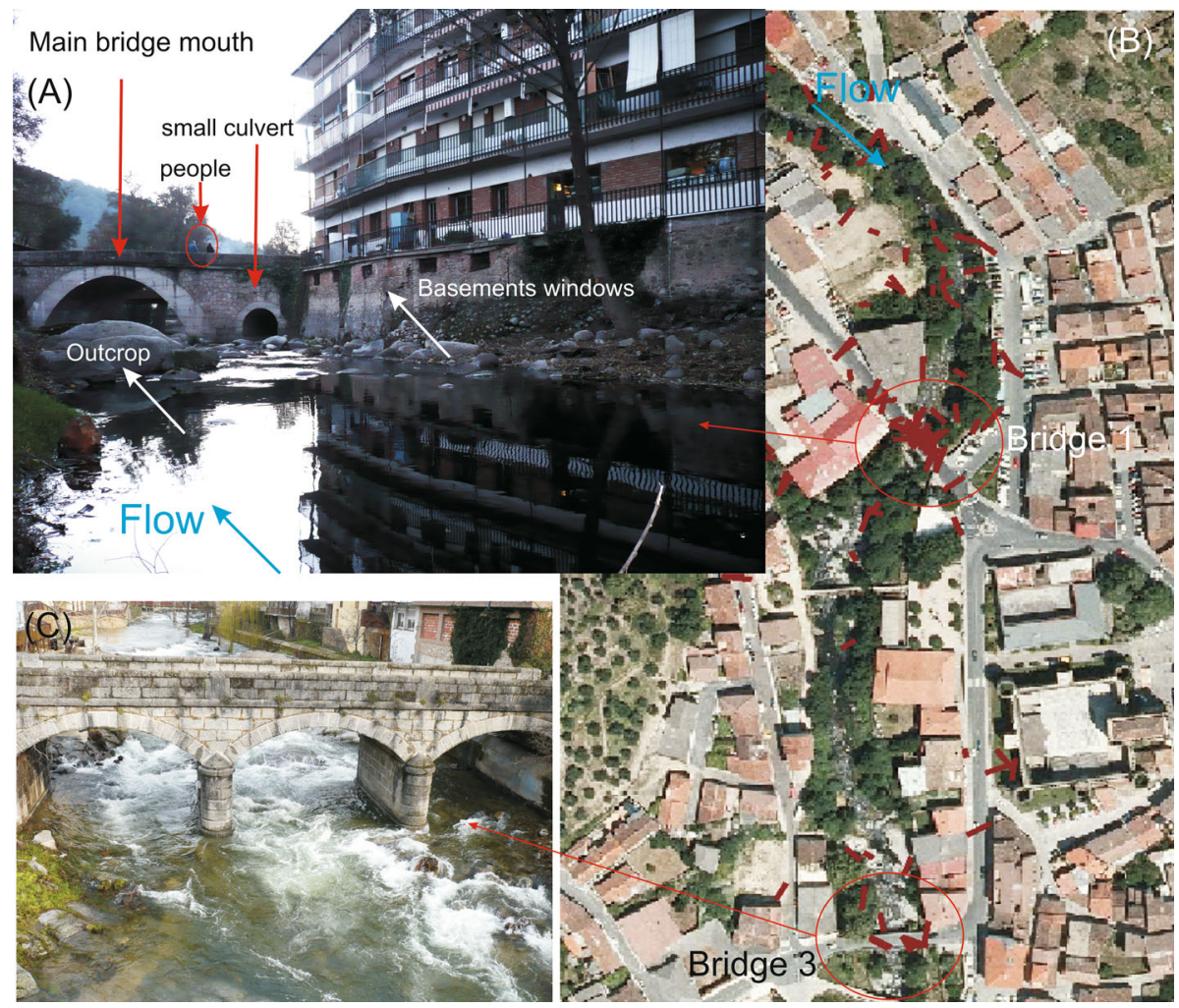

Fig. 7 Simulation result for scenario 2. Wood deposits at critical stream configurations (b), particularly at bridges 1 (a) and 3 (c)

Table 3 Main characteristics of the 3 bridges and the cross-sectional water depth for the four scenarios

\begin{tabular}{lcllllll}
\hline Section & Deck high $(\mathrm{m})$ & Base width $(\mathrm{m})$ & \multicolumn{2}{l}{ Water depth $(\mathrm{m})$} & \multirow{2}{*}{ Geometry } \\
\cline { 4 - 6 } & & & No wood & SC1 & SC2 & SC3 & \\
\hline Bridge 1 & 7 & 11 & 6.6 & 8.5 & 9.1 & 9.7 & Single arch \\
Bridge 2 & $5^{\text {a }}$ & 18 & 7.7 & 8.3 & 8.4 & 8.6 & Rectangular \\
Bridge 3 & 6 & 14 & 4.8 & 4.9 & 7.4 & 9.0 & 3 Archs and 2 pillars
\end{tabular}

a Embankment is up to $8 \mathrm{~m}$

The car park area located in the left side and nearby the bridge 1 section has an approx. capacity for 75 vehicles, although there are also other parking areas. But just considering this area, and the average market price of $12,000 €$ per vehicle, the potential damages may be as high as 400,000-500,000 $€$ (with $85 \%$ probability), but if wood transport is included in the simulation, this value increases to $700,000 €$.

In addition, we analysed the human danger zone (based on water depth and flow velocity; Fig. 11) and the potential transport capacity of the flow (in terms of potentially mobile sediment diameter), which could both be important factors in an evacuation process. 

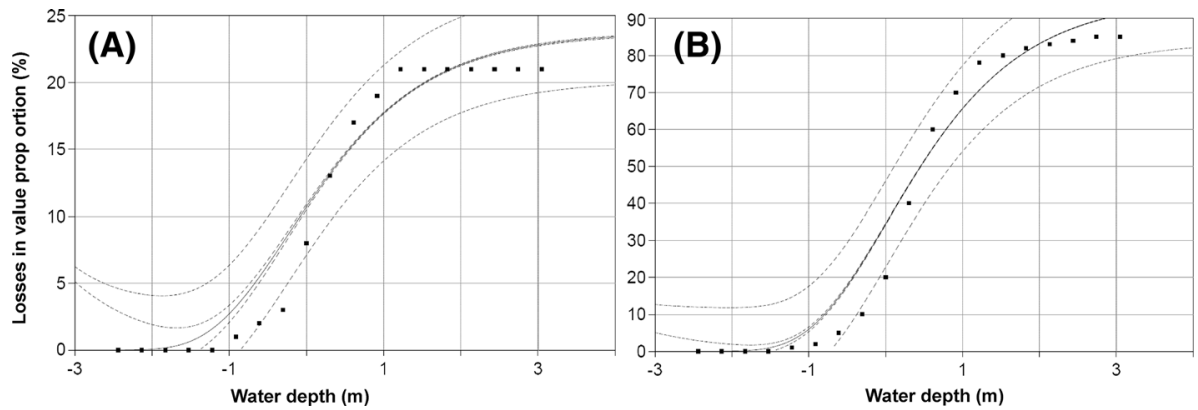

Fig. 8 Examples of the damage functions used in this analysis. a Structural vulnerability b contents vulnerability (depth-damage functions) for one-storey residential buildings with basement
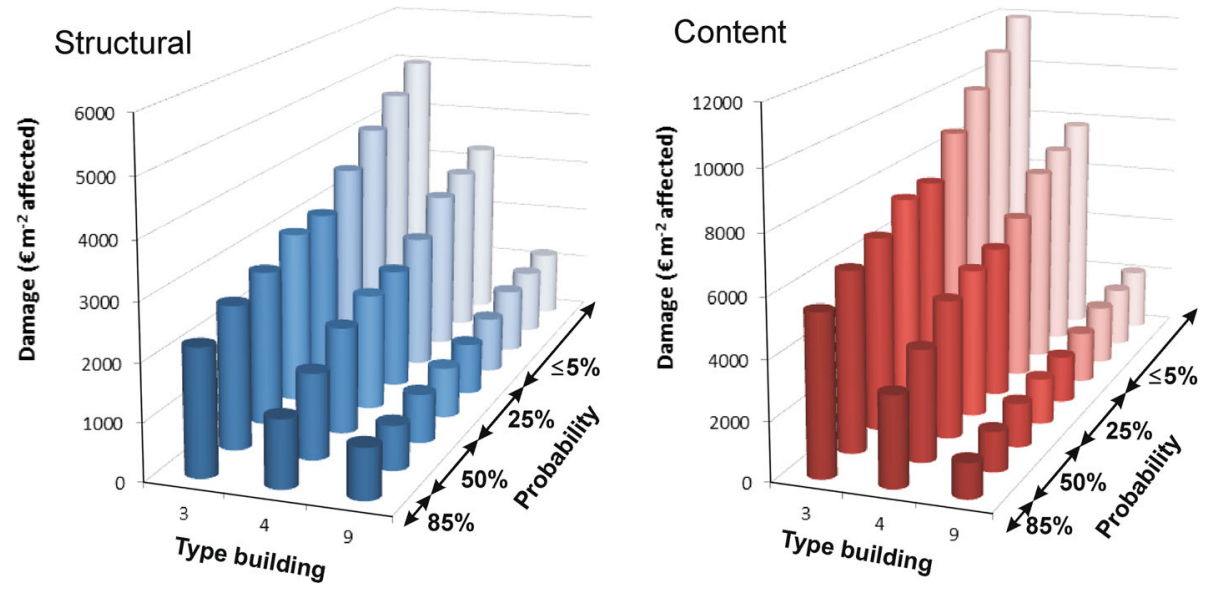

Fig. 9 Potential damage to the structure and content of the three main types of buildings in the area based on simulation without wood

For the worst-case wood transport scenario (SC3), the transport capacity does not change significantly. The backwater effect in the flooded areas means that the flow has a very low transport capacity. However, the human danger zone increases significantly, particularly in the area marked in Fig. 11 with an ellipse, where the effect of bridge clogging causes inundation. In this area, not only the increase in water depth but also the flow velocity makes walking difficult and potentially harmful for people.

\section{Discussion}

Large wood is an additional hazard during floods, considerably increasing their destructive power (Schmocker and Weitbrecht 2013). Risk analysis and proper management measures are therefore key elements to minimize potential damage. This paper uses a probabilistic approach to numerical modelling to analyse the potential impacts of large wood transport and deposition on flood risk in a mountain village in Central Spain. Since this process has 


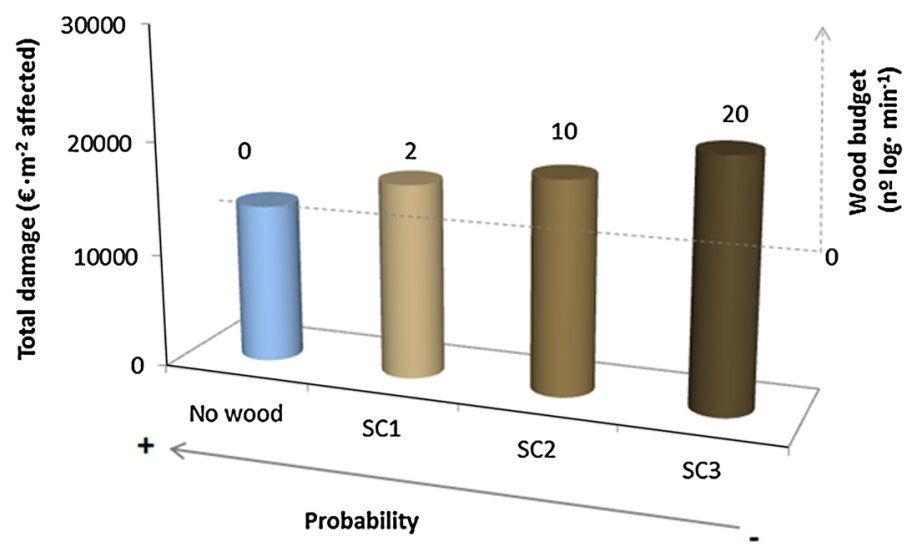

Fig. 10 Potential estimated damage for the four scenarios, 500-year flood with no wood transport, and the three scenarios for wood transport
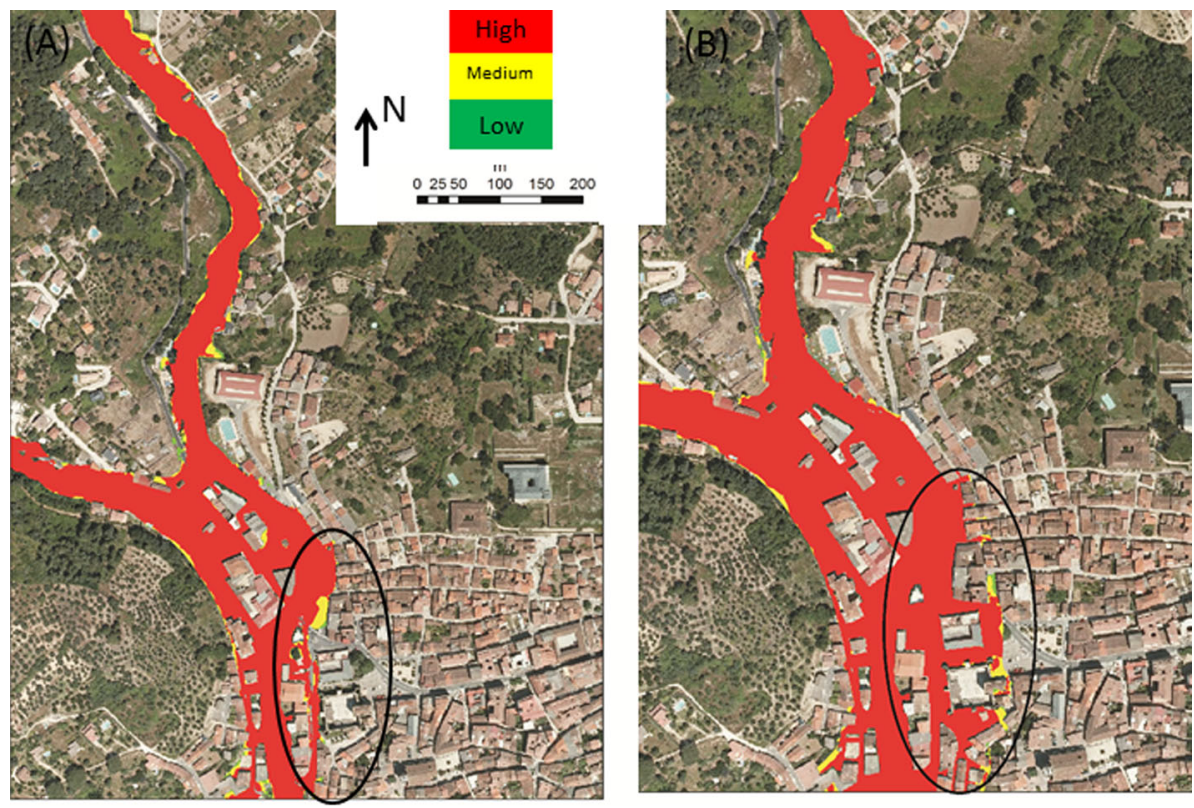

Fig. 11 a Danger zone for people without wood and $\mathbf{b}$ scenario 3 of wood transport. Maps are related to the $90 \%$ probability 500-year flood

considerable intrinsic uncertainty, the probabilistic thinking was complemented by possibilistic thinking, including the worst-case scenario. As outlined in the introduction, there is a lack of direct observations of wood transport during extreme floods, and in general, wood is not considered in flood risk management in Spain. Therefore, the method presented here was used to test the potential role of large wood in flood risk by evaluating different scenarios. We evaluated the worst-case scenario, but different scenarios can also be designed. We are aware that the use of worst-case scenarios is problematic and decision 
makers often refuse to consider them, since they are perceived as unrealistic. But we think that the value of including worst-case scenarios in situations where there is considerable uncertainty is an additional dimension that this process adds to risk assessment and risk management strategies (Merz et al. 2010).

We based most of the work on models, as they may provide an alternative approach to addressing some of the unknowns regarding wood dynamics. The model represents a controllable virtual world which tries to replicate the real world (with limitations and uncertainties). This virtual world can be analysed fully in any space and at any time and can be used to test hypotheses and to run scenarios, such as this case.

As a result of this work, the infrastructures most sensitive to the passing of large wood have been identified, as well as the consequences of their blockage due to the increase in the water level and flooded areas nearby.

The most important input parameter when wood transport is evaluated is the quantity of transported wood for a given flood event. Although several empirical methods exist to predict the potential wood delivered for a given catchment (Rickenmann 1997), a comparison with field data indicates a large scatter (Waldner et al. 2007; Bezzola and Hegg 2007). A detailed study of the catchment is therefore necessary for project planning. We used a GIS-based approach in combination with fuzzy logic principles to design the wood budget based on potential susceptibility to landslides, floods and bank erosion (based on previous works by Ruiz-Villanueva et al. 2014a). The methodology incorporates so-called vegetation resistance and the severity of the recruitment process together with the concept of vegetation resistance and the volume correction factor. This concept may be equivalent to the structural classification of forested areas posited by Blaschke et al. (2004) and the large wood availability indicator used by Mazzorana et al. (2010). The volume correction factor can be a source of subjectivity, and modification of this coefficient could change the final results. In addition, we acknowledge some limitations of the conceptual model, and probably one of the most striking findings is the validation of volume estimations. Although exact numbers are obtained, they cannot be validated but should be assumed as order of magnitude. Moreover, a range was considered to take the uncertainty into account.

Together with the quantity of wood transported, the 500-year flood was assumed as the worst-case flood scenario. Several studies indicate that the source of most uncertainties in flood risk assessment is the incomplete understanding of the flood-frequency law (Merz et al. 2010; Apel et al. 2004). For this purpose, a Bayesian Markov chain Monte Carlo (MCMC) framework (Kuczera 1999; Reis and Stedinger 2005; Gaál et al. 2010; Gaume et al. 2010) was used and a likelihood function was built to handle the information on historical floods properly. This analysis revealed large differences in quantile estimation of the 500-year quantile. Underestimating this value may result in risk underestimation, but at the same time, overestimating it could result in financial and risk management overestimation. Because of this uncertainty in the quantile estimation, flood hazard maps have been produced using a probability approach (Romanowicz and Beven 2003; Bates et al. 2004; Pappenberger et al. 2006). Our further research focused on the 500-year flood scenario, and the 2D hydraulic model was applied to compute the hydrodynamics and wood transport. There was no rating curve or any other data available to calibrate the hydraulic model, and water depth was analysed under uncertainty of the input Manning roughness coefficient values. The value range was treated as normally distributed but using a fuzzy set approach. Komatina (2005) compares this method with a Monte Carlo simulation and found them highly comparable, with both methods giving almost the same results. When input parameters are treated as random variables with known probability distributions (Apel et al. 2004), the uncertainty is described in the most informative, but also the strictest way. 
But if no prior information regarding the parameter probability distribution is available, an alternative approach could be used instead, based on the imprecise probability (i.e. fuzzy set approach), in which some probability theory axioms are relaxed (Fellin et al. 2005).

The establishment of different wood transport scenarios allowed us to study the influence of the inlet boundary conditions on the wood clogging of bridges and their potential impacts. As expected, steady transport (SC1) is associated with a lower probability of blocking, whereas congested transport (SC3) resulted in the highest blocking rate.

Although the only stochastic component in the model is the assessment of log shape (based on established ranges) in the inlet boundary conditions and the effect of turbulence, simulating the same scenario of wood transport several times can result in slightly different random log interactions and blocking processes. The final logs forming the deposits may also vary for each simulation. But the likely depositional areas should be the same since these areas are mainly defined by the river morphology and the flood hydrodynamics.

The shape of logs (as cylinders, disregarding the effect of branches or roots) is the main simplification assumed by the model. This geometry can be a good approximation for key pieces or non-rooted and defoliated trees (Braudrick et al. 1997; Bocchiola et al. 2008; Buxton 2010), although according to the findings of Schmocker and Hager (2010), the probability of blocking may increase with the presence of roots, and log trajectories may be different.

In order to estimate the damaged share of the asset values, depending on water depth (influenced by the presence of wood), relative depth-damage functions have to be applied. Such damage functions show the average susceptibility of each sector against inundation depth. Since there was no organized systematic collection of flood damage data in Arenas de San Pedro, we used functions based on those used in other similar regions in Spain and computed predictive bounds to take the uncertainty into account. Some studies apply aggregated values from insurance companies. For example, in the Netherlands use an approximate value of 70,000 € per flat (year 2000). German studies (e.g. Reese et al. 2003) often apply an average value of $700 €$ per $\mathrm{m}^{2}$ of living area (full replacement value) or 350 $€$ per $\mathrm{m}^{2}$ (depreciated value) which also come from an insurance company. The values we used are reliable approximations, but the calculations are in $€ \mathrm{~m}^{-2}$ because the aim of this study was to make a probabilistic evaluation of uncertainty and to analyse the influence of wood transport. The goal was to compare values, not to obtain exact monetary losses.

\section{Conclusions}

The presence of wood during a flood may influence the consequences and potential damage of flooding, as demonstrated in this work. The main effect is the obstruction of crosssectional areas particularly in critical sections such as bridges, which can trigger the inundation of nearby areas. As a result, the flooded areas and flow conditions are different from those defined in the absence of wood. Transport and deposition of wood in forested mountain basins should therefore not be ignored in flood risk assessment. However, a lack of direct observations makes it difficult to address this process. Models can be used to address some of the uncertainties related to wood dynamics, but field data and an in-depth knowledge of the riparian forest and in-stream wood must be obtained to establish inlet boundary conditions and appropriately validate results. As this empirical data are not always available, models may still be used as an alternative and supplementary tool for generating scenarios. It is particularly important for practitioners who must assess and manage flooding risks associated with wood to identify wood delivery sources and 
potentially critical sections (i.e. infrastructures). However, systematic analysis still requires considerable research.

Acknowledgments This work was funded by CICYT MAS Dendro-Avenidas project (CGL 2010-19274) and the Geological Survey of Spain (IGME). We are grateful to the Confederación Hidrográfica del Tajo and Meteorological Agency (AEMET) for having provided meteorological data; the Junta de Castilla y León in Ávila, Ayuntamiento de Arenas de San Pedro (particularly to Nuria Blázquez, Gloria Suárez and Sixto Díaz) for their collaboration. Special mention to Martí Sánchez-Juni (UPC) for his collaboration; and to Ignacio Gutiérrez, Luis Fernández and Luis Barca for their assistance with the topographical survey.

\section{References}

Abt SR, Wittler RJ, Taylor A, Love DJ (1989) Human stability in a high hazard flood zone. Water Resour Bull 25(4):881-890

Apel H, Thieken AH, Merz B, Blöschl G (2004) Flood risk assessment and associated uncertainty. Nat Hazards Earth Syst Sci 4:295-308

Ballesteros-Canovas JA, Sanchez-Silva M, Bodoque JM, Diez-Herrero A (2013) An integrated approach to flood risk management: a case study of navaluenga (Central Spain). Water Resour Manage 27:3051-3069

Bates PD, Horritt MS, Aronica G, Beven K (2004) Bayesian updating of flood inundation likelihoods conditioned on flood extent data. Hydrol Process 18:3347-3370

Bezzola GR, Hegg C (eds) (2007) Ereignisanalyse Hochwasser 2005. Teil 1 Prozesse, Schäden und erste Einordnung. Bundesamt für Umwelt BAFU, Eidgenössische Forschungsanstalt WSL. Umweltwissen 0707, Bern

Bladé E, Cea L, Corestein G, Escolano E, Puertas J, Vázquez-Cendón ME, Dolz J, Coll A (2012) Iber Herramienta de simulación numérica del flujo en ríos. Rev Int Metod Numer 30:1-10

Blaschke T, Burnett C, Pekkarinen A (2004) New contextual approaches using image segmentation for object-based classification. In: De Meer F, de Jong S (eds) Remote sensing image analysis: including the spatial domain. Kluver Academic Publishers, Dordrecht, pp 211-236

Bocchiola D, Rulli M, Rosso R (2006) Transport of large woody debris in the presence of obstacles. Geomorphology 76:166-178

Bocchiola D, Rulli MC, Rosso R (2008) A flume experiment on the formation of wood jams in rivers. Water Resour 44:1-17

Bradley C, Mosugu M, Gerrard AJ (2005) Simulation modelling of water movement in a cracking clay soil. Soil Use Manag 21:386-395

Braudrick CA, Grant GE, Ishikawa Y, Ikeda H (1997) Dynamics of wood transport in streams: a flume experiment. Earth Surf Proc Land 22:7

Brooks AP, Abbe T, Cohen T, Marsh N, Mika S, Boulton A, Broderick T, Borg D, Rutherfurd I (2006) Design guidelines for the reintroduction of wood into Australian streams. Land \& Water Australia, Canberra

Buxton TH (2010) Modelling entrainment of waterlogged large wood in stream channels. Water Resour Res 46:10

Chow VT (1959) Open-channel hydraulics. McGraw-Hill, New York

Comiti F, Mao L, Wilcox A, Wohl E, Lenzi M (2007) Field-derived relationships for flow velocity and resistance in high-gradient streams. J Hydrol 340:48-62

Comiti F, Agostino VD, Moser M, Lenzi MA, Bettella F, Agnese AD, Rigon E, Gius S, Mazzorana B (2012) Preventing wood-related hazards in mountain basins: from wood load estimation to designing retention structures. In: 12th congress INTERPRAEVENT 2012-Grenoble/France conference proceedings, pp 651-662

Di Baldassarre G, Schumann G, Bates P, Freer J, Beven K (2010) Floodplain mapping: a critical discussion on deterministic and probabilistic approaches. Hydrol Sci J 55(3):364-376

Diehl TH (1997) Potential drift accumulation at bridges, FHWA-RD-97-28. U.S. Department of Transportation, Federal Highway Administration, Washington

Dudley SJ, Fischenich JC, Abt SR (1998) Effect of woody debris entrapment on flow resistance. J Am Water Resour As 34:1189-1197

Faulkner H, Parker D, Green C, Beven K (2007) Developing a translational discourse to communicate uncertainty in flood risk between science and the practitioner. Ambio 36:692-703

Fellin W, Lessmann H, Oberguggenberger M, Vieider R (2005) Analysing uncertainty in civil engineering. Springer, Berlin. ISBN 3-540-22246-4 
Gaál L, Szolgay J, Kohnová S, Hlavcová K, Viglione A (2010) Inclusion of historical information in flood frequency analysis using a Bayesian MCMC technique: a case study for the power dam Orlík, Czech Republic. Contrib Geophys Geod 40:121-147

Gaume E, Gaál L, Viglione A, Szolgay J, Kohnova S, Blöschl G (2010) Bayesian MCMC approach to regional flood frequency analyses involving extraordinary flood events at ungauged sites. J Hydrol 394:101-117

Gippel CJ (1995) Environmental hydraulics of large woody debris in streams and rivers. J Environ Eng ASCE 121:388-395

Gómez M, Macchione F, Russo B (2010) Hazard criteria related to urban flooding produced by heavy storm events. In: Proceedings of 1st European congress of the IAHR. Edinburgh, May 4-6

Haque CE, Etkin D (2007) People and community as constituent parts of hazards: the significance of societal dimensions in hazards analysis. Nat Hazards 41:271-282

Jarrett RD, (1990) Paleohydrology used to define the spatial occurrence of floods. Geomorphol 3:81-95

Kang JL, Su MD, Chang LF (2005) Loss functions and frame-work for regional flood damage estimation in residential area. J Mar Sci Technol 13:193-199

Kelman I, Thomalla F, Brown J, Möller I, Spence R, Spencer T (2002) Coastal flood-risk assessment in England. Philos Trans R Soc Lond A360(1796):1553-1554

Komatina D (2005) Uncertainty analysis as a complement to flood risk assessment. http://daad.wb. tuharburg.de/fileadmin/BackUsersResources/Risk/Dejan/UncertaintyAnalysis.pdf

Kreibich H, Seifert I, Merz B, Thieken AH (2010) Development of FLEMOcs-a new model for the estimation of flood losses in the commercial sector. Hydrol Sci 55(8):1302-1314

Kuczera G (1999) Comprehensive at-site flood frequency analysis using Monte Carlo Bayesian inference. Water Resour Res 35(5):1551-1557

Lassettre NS, Kondolf GM (2012) Large woody debris in urban stream channels: redefining the problem. River Res Appl 28:1477-1487

LeVeque RJ (2002) Finite volume methods for hyperbolic problems. Cambridge University Press, Cambridge

Lyn D, Cooper T, Condon D, Gan L (2007) Factors in debris accumulation at bridge piers. Department of Transportation, Federal Highway Administration Research and Development, Turner-Fairbank Highway Research Center, Washington

Manga M, Kirchner JW (2000) Stress partitioning in streams by large woody debris. Water Resour 36:2373-2379

Mao L, Comiti F (2010) The effects of large wood elements during an extreme flood in a small tropical basin of Costa Rica. In: De Wrachien D, Brebbia CA (eds) Debris flow III. WIT Press, UK, pp 225-236

Martin DJ, Benda LE (2001) Patterns of in-stream wood recruitment and transport at the watershed scale. Trans Am Fish Soc 130:940-958

May CL, Gresswell RE (2003) Large wood recruitment and redistribution in headwater streams in the southern Oregon Coast Range, U.S.A. Can J For Res 33:1352

Mazzorana B, Hübl J, Zischg AM, Largiader A (2010) Modelling woody material transport and deposition in alpine rivers. Nat Hazards 56:425-449

Mazzorana B, Comiti F, Volcan C, Scherer C (2011) Determining flood hazard patterns through a combined stochastic-deterministic approach. Nat Hazards 59:301-316

Merz B, Thieken AH, Blöschl, G (2002) Uncertainty analysis for flood risk estimation. In: Spreafico M, Weingartner R. (eds) International conference on flood estimation. CHR Report II-17, pp 577-585

Merz B, Thieken AH, Gocht M (2007) Flood risk mapping at the local scale: concepts and challenges. In: Begum S, Stive MJF, Hall JW (eds) Flood risk management in Europe: innovation in policy and practice. Series: advances in natural and technological hazards research, vol 25. Springer, Dordrecht, Chapter 13, pp 231-251

Merz B, Hall J, Disse M, Schumann A (2010) Fluvial flood risk management in a changing world. Nat Hazards Earth Syst Sci 10:509-527. doi:10.5194/nhess-10-509-2010

Messner F, Meyer V (2005) Flood damage, vulnerability and risk perception. Challenges for flood damage research. UFZ, Leipzig $26 \mathrm{p}$

Messner F, Penning-Rowsell E, Green C, Meyer V, Tunstall S, van der Veen A (2007) Guide- lines for socio-economic flood damage evaluation. FLOODsite-Report T09-06-01, $176 \mathrm{pp}$

MFE (2011) El Mapa Forestal de España 1:25000 (MFE), Ministerio de Agricultura, Alimentación y Medio Ambiente (MARM). http://www.magrama.es/es/biodiversidad/temas/montes-y-politica-forestal/mapaforestal/mfe_25.aspx

NRC (National Research Council) (2000) Risk analysis and uncertainty in flood damage reduction studies. National Academy Press, Washington

Ollero A (2013) ¿Por qué NO hay que limpiar los ríos? http://river-keeper.blogspot.ch/2013/01/por-que-nohay-que-limpiar-los-rios.html 
Pappenberger F, Frodsham K, Beven J, Frodsham K, Romanovicz R, Matgen P (2006) Fuzzy set approach to calibrating distributed flood inundation models using remote sensing observations. Hydrol Earth Syst Sci Discuss 3:2243-2277

Paté-Cornell ME (1996) Uncertainties in risk analysis: six levels of treatment. Reliab Eng Syst Saf 54:95-111

PATRICOVA (2002) Plan de acción territorial de carácter sectorial sobre prevención del riesgo de inundación en la comunidad valenciana. Documento No 1. Dirección General de Urbanismo y Ordenación Territorial, Generalitat Valenciana, Valencia

Reese S, Markau HJ, Sterr H (2003) MERK-Micro-scale evaluation of risks in flood-prone coastal lowlands. Research project on commission of the Federal Ministry of Research and the State of SchleswigHolstein Government

Reis DS, Stedinger JR (2005) Bayesian MCMC flood frequency analysis with historical information. J Hydrol 313(1-2):97-116. doi:10.1016/j.jhydrol.2005.02.028

Reiter P (2000) International methods of risk analysis, damage evaluation and social impact studies concerning dam-break accidents. PR Water Consulting, Helsinki

Rickenmann D (1997) Schwemmholz und hochwasser. Wasser Energie Luft 89(5/6):115-119

Robison EG, Beschta RL (1990) Identifying trees in riparian areas that can provide coarse woody debris to streams. For Sci 36:790-801

Romanowicz R, Beven KJ (2003) Bayesian estimation of flood inundation probabilities as conditioned on event inundation maps. Water Resour Res 39:3

Ruiz-Villanueva V, Bodoque JM, Díez-Herrero A, Eguibar MA, Pardo-Igúzquiza E (2012) Reconstruction of an ungauged flash flood event with large wood transport and its influence on hazard patterns. Hydrol Process. doi:10.1002/hyp.9433

Ruiz-Villanueva V, Díez-Herrero A, Bodoque JM, Ballesteros JA, Stoffel M (2013) Characterization of flash floods in small ungauged mountain basins of central Spain using an integrated approach. Catena 110:32-43

Ruiz-Villanueva V, Bladé-Castellet E, Sánchez-Juny M, Martí B, Díez Herrero A, Bodoque JM (2014a) Two dimensional numerical modelling of wood transport. J Hydroinf. doi: 10.2166/hydro.2014.026

Ruiz-Villanueva V, Díez-Herrero A, Ballesteros JA, Bodoque JM (2014b) Potential Large Woody Debris recruitment due to landslides, bank erosion and floods in mountain basins: a quantitative estimation approach. River Res Appl 30:81-97

Russo B, Gómez M, Macchione F (2011) Experimental approach to determine flood hazard criteria in urban areas. 12th international conference on urban drainage, Porto Alegre/Brazil, 10-15 September 2011

Schmocker L, Hager W (2010) Drift accumulation at river bridges. In: Dittrich A, Koll K, Aberle J, Geisenhainer P (eds) River flow 2010. Bundesanstalt für Wasserbau

Schmocker L, Hager W (2011) Probability of drift blockage at bridge decks. J Hydraul Eng 137(4):470-479

Schmocker L, Weitbrecht V (2013) Driftwood: risk analysis and engineering measures. J Hydraul Eng 139(7):683-695

Shand TD, Cox RJ, Blacka MJ, Smith GP (2010) Appropriate safety criteria for vehicles 14. Report number: P10/S1/006. Australian Rainfall and Runoff, $28 \mathrm{pp}$

Swanson FJ (2003) Wood in rivers: a landscape perspective. Am Fish Soc Symp 37:299-313

Yen BC, Tung YK, (1993) Some recent progress in reliability analysis for hydraulic design. In: Yen BC, Tung YK. (eds) Reliability and uncertainty analysis in hydraulic design: A report prepared by the subcommittee on uncertainty and reliability analysis in design of hydraulic structures of the technical committee on probabilistic approaches to hydraulics. ASCE, New York, pp 35-79

USACE (1992) (U.S. Army Corps of Engineers). Guidelines for risk and uncertainty analysis in water resources planning. Institute for Water Resources, IWR report 92-R-1, Fort Belvoir, VA

Versteeg HK, Malalasekera W (2007) An introduction to computational fluid dynamics. Pearson Education Limited, Harlow. ISBN 978-0-13-127498-3

Waldner P, Rickli C, Köchli D, Usbeck T, Schmocker L, Sutter F (2007) Schwemmholz [driftwood]. In: Bezzola GR, Hegg C (eds) Umwelt-Wissen 0707, pp 181-193 (in German)

Wallingford HR (2005) The flood risk to people methodology. Flood risks to people, phase 2 R\&D output FD2321/TR1. Defra/Environment Agency Flood and Coastal Defence R\&D Programme

Wind HG, Nierop TM, de Blois CJ, de Kok JL (1999) Analysis of flood damages from the 1993 and 1995 Meuse floods. Water Resour Res 35(11):3459-3465

Yeo SW (1998) Controls on flood damages, Ba River Valley, Fiji. Unpublished Ph.D. thesis, Natural Hazards Research Centre, School of Earth Sciences, Macquarie University

Young WJ (1991) Flume study of the hydraulic effects of large woody debris in lowland rivers. Regul Rivers Res Manag 6:203-212 